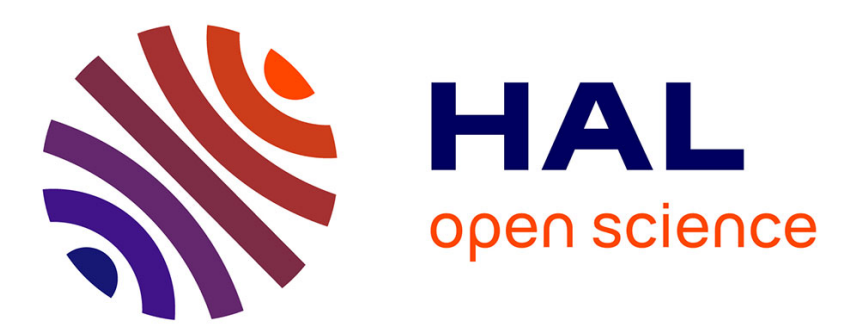

\title{
Structural study of the function of Candida Albicans Pif1
}

\author{
Ke-Yu Lu, Ben-Ge Xin, Teng Zhang, Na-Nv Liu, Dan Li, Stephane Rety, \\ $\mathrm{Xu}$-Guang Xi
}

\section{- To cite this version:}

Ke-Yu Lu, Ben-Ge Xin, Teng Zhang, Na-Nv Liu, Dan Li, et al.. Structural study of the function of Candida Albicans Pif1. Biochemical and Biophysical Research Communications, 2021, 567, pp.190 194. 10.1016/j.bbrc.2021.06.050 . hal-03322963

\section{HAL Id: hal-03322963 https://hal.science/hal-03322963}

Submitted on 20 Aug 2021

HAL is a multi-disciplinary open access archive for the deposit and dissemination of scientific research documents, whether they are published or not. The documents may come from teaching and research institutions in France or abroad, or from public or private research centers.
L'archive ouverte pluridisciplinaire HAL, est destinée au dépôt et à la diffusion de documents scientifiques de niveau recherche, publiés ou non, émanant des établissements d'enseignement et de recherche français ou étrangers, des laboratoires publics ou privés. 


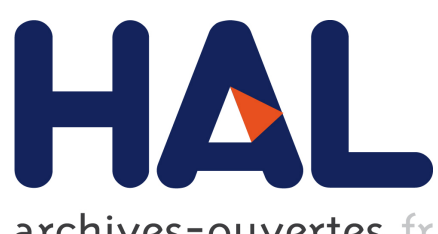

archives-ouvertes

\title{
Structural study of the function of Candida Albicans Pif1
}

\author{
Ke-Yu Lu, Ben-Ge Xin, Teng Zhang, Na-Nv Liu, Dan Li, Stephane Rety, \\ Xu-Guang Xi
}

\section{To cite this version:}

Ke-Yu Lu, Ben-Ge Xin, Teng Zhang, Na-Nv Liu, Dan Li, et al.. Structural study of the function of Candida Albicans Pif1. Biochemical and Biophysical Research Communications, Elsevier, 2021, 567, pp.190 - 194. 10.1016/j.bbrc.2021.06.050 . hal-03322963

\section{HAL Id: hal-03322963 \\ https://hal.archives-ouvertes.fr/hal-03322963}

Submitted on 20 Aug 2021

HAL is a multi-disciplinary open access archive for the deposit and dissemination of scientific research documents, whether they are published or not. The documents may come from teaching and research institutions in France or abroad, or from public or private research centers.
L'archive ouverte pluridisciplinaire $\mathbf{H A L}$, est destinée au dépôt et à la diffusion de documents scientifiques de niveau recherche, publiés ou non, émanant des établissements d'enseignement et de recherche français ou étrangers, des laboratoires publics ou privés. 


\section{Biochemical and Biophysical Research Communications Structural study of the function of Candida Albicans Pif1 --Manuscript Draft--}

\begin{tabular}{|l|l|}
\hline Manuscript Number: & BBRC-21-3484 \\
\hline Article Type: & Short communication/Research article \\
\hline Keywords: & Pif1 helicase; Crystal structure; Unwinding activity; Conformational change \\
\hline Corresponding Author: & $\begin{array}{l}\text { Xu-Guang Xi } \\
\text { Northwest Agriculture and Forestry University } \\
\text { Yangling, CHINA }\end{array}$ \\
\hline First Author: & Ke-Yu Lu \\
\hline Order of Authors: & Ke-Yu Lu \\
\hline & Ben-Ge Xin \\
\hline & Teng Zhang \\
\hline & Na-Nv Liu \\
\hline & Dan Li \\
\hline & Stephane Rety \\
\hline & Xu-Guang Xi \\
\hline
\end{tabular}




\section{Structural study of the function of Candida Albicans Pif1}

Ke-Yu Lu ${ }^{a, \dagger}$, Ben-Ge Xin ${ }^{a, \uparrow}$, Teng zhang ${ }^{a}$, Na-Nv Liu ${ }^{a}$, Dan Lia, Stephane Rety ${ }^{b}$, and XuGuang $\mathbf{X i}^{\mathbf{a}, \mathbf{c}, *}$

${ }^{a}$ College of Life Sciences, Northwest A\&F University, Yangling, Shaanxi 712100, China;

b Univ. Lyon, ENS de Lyon, Univ. Claude Bernard, CNRS UMR 5239, INSERM U1210, LBMC, 46 allée d'Italie Site Jacques Monod, F-69007, Lyon, France;

${ }^{\mathrm{c}}$ LBPA, Ecole Normale Supérieure Paris-Saclay, CNRS, Université Paris Saclay, Gif-sur-Yvette, France

Footnotes:

${ }^{\dagger}$ These authors contributed equally to this work.

${ }^{*}$ Corresponding author. College of Life Sciences, Northwest A\&F University, Yangling, Shaanxi 712100, China.

Email address: xxi01@ens-cachan.fr (X-G Xi) 


\begin{abstract}
Pif1 helicases, conserved in eukaryotes, are involved in maintaining genome stability in both the nucleus and mitochondria. Here, we report the crystal structure of a truncated Candida Albicans Pif1 $\left(\mathrm{CaPif}^{368-883}\right)$ in complex with ssDNA and an ATP analog. Our results show that the Q-motif is responsible for identifying adenine bases, and CaPif1 preferentially utilizes ATP/dATP during dsDNA unwinding. Although CaPif1 shares structural similarities with Saccharomyces cerevisiae Pif1, CaPif1 can contact the thymidine bases of DNA by hydrogen bonds, whereas ScPif1 cannot. More importantly, the crosslinking and mutant experiments have demonstrated that the conformational change of domain 2B is necessary for CaPifl1 to unwind dsDNA. These findings contribute to further the understanding of the unwinding mechanism of Pif1.
\end{abstract}

Keywords: Pif1 helicase; Crystal structure; Unwinding activity; Conformational change 


\section{Introduction}

Helicases are almost ubiquitous enzymes involved in multiple aspects of DNA and RNA metabolism. Helicases are classified into 6 superfamilies, SF1 to SF6, based on the conserved helicase motifs. In each superfamily, the helicases are categorized into subgroups A and B according to the directionality of their translocation along nucleic acids [1].

Pif1, a DNA helicase of the SF1B, is widely found in eukaryotes from yeast to humans [2, 3]. For example, ScPif1 (Saccharomyces cerevisiae Pif1), as the founding member of the Pif1 family, has multiple in vivo functions, such as maintaining mitochondrial DNA [4], inhibiting telomerase [5, 6], processing Okazaki fragments [7], and resolving G-quadruplex (G4) structures [8, 9].

Based on sequence alignments, Pif1 protein can be broadly divided into 3 parts, the central helicase core and the N-terminal and C-terminal accessory domains. Although the 2 accessory domains vary in length and sequence between species, they are required for the helicase's in vivo and in vitro functions [3]. For example, the N-terminal domain of ScPif1 is essential for Rim1's stimulation of Pif1-catalyzed strand separation activity [10]. The N-terminal domain of human Pif1 (hPif1) possesses ssDNA annealing activity [11]. On the other hand, ScPif1's C-terminal domain promotes the processivity of DNA unwinding [12].

The helicase core, evolutionarily conserved in various organisms, comprises 2 RecA-like domains, $1 \mathrm{~A}$ and 2A, and 2 additional domains, $1 \mathrm{~B}$ and 2B [13]. The 1B domain, consisting of a loop and an $\alpha$-helix, is inserted into 1A; 2B, which forms an SH3-like domain, is inserted into 2A. The helicase core is the basic unit with which Pif1 protein exerts its helicase activity. During dsDNA unwinding, the 1A and 2A domains bind the $5^{\prime}$-tail of a dsDNA and begin to translocate along the single strand in a $5^{\prime} \rightarrow 3^{\prime}$ direction driven by ATP hydrolysis [1]. In this case, 1B is believed to form a pin or wedge that splits the incoming duplex [14]. In recent years, structures of Bacteroides spp. (Bs) and Thermus oshimai Pif1(ToPif1) with and without ligands binding have been solved, and domain 2B has been found to undergo a significant conformation change upon DNA and ATP binding [15-17].

Here, we described a ternary complex structure of CaPif1 helicase core bound to ssDNA and ADP.AlF 4 . The structural snapshots and biochemical analyses revealed some characteristics of CaPif1 in dsDNA unwinding, ssDNA binding, and ATP hydrolysis. 


\section{Materials and methods}

\subsection{Protein expression and purification}

The gene encoding the Candida albicans Pif1 helicase core (CaPif1 ${ }^{368-883}$, "CaPif1" for short) was generated by PCR and cloned into a modified pET-15b vector (Invitrogen) with an N-terminal SUMO tag to generate His-SUMO-CaPif1. The construct was transformed into E. coli $\mathrm{C} 2566 \mathrm{H}$ (New England Biolabs). The cells were grown in LB medium containing $100 \mu \mathrm{g} / \mathrm{mL}$ ampicillin at $37^{\circ} \mathrm{C}$ to $\mathrm{OD}_{600}$ of 0.7 and induced with $0.4 \mathrm{mM}$ IPTG at $18^{\circ} \mathrm{C}$ for an additional $16 \mathrm{~h}$. The cells were then harvested, resuspended in a lysis buffer $[25 \mathrm{mM}$ Tris- $\mathrm{HCl}(\mathrm{pH} 7.8), 500 \mathrm{mM} \mathrm{NaCl}, 10 \%$ (v/v) glycerol, $5 \mathrm{mM}$ imidazole and $1 \mathrm{mM}$ EDTA], homogenized with a French press (1000 bar) 3 times, and sonicated 2-3 times to shear their DNA. After centrifugation and filtration using a $0.45-\mathrm{mm}$ membrane, the clarified cell lysate was loaded onto a cOmplete His-Tag Purification Column (CHTPR, Roche) equilibrated with the lysis buffer at $18^{\circ} \mathrm{C}$. His-SUMO-CaPif1 was eluted in a gradient increased to $300 \mathrm{mM}$ imidazole over 20 column volumes (cv). The identified fractions were incubated with SUMO protease and dialyzed with the dialysis buffer [25 mM Tris- $\mathrm{HCl}(\mathrm{pH} 7.6), 500 \mathrm{mM} \mathrm{NaCl}$ and $10 \%(\mathrm{v} / \mathrm{v})$ glycerol] at $18^{\circ} \mathrm{C}$ overnight. Protein was then diluted to $150 \mathrm{mM} \mathrm{NaCl}$ with the dilution buffer $[25 \mathrm{mM}$ Tris- $\mathrm{HCl}$ (pH 7.6), $20 \mathrm{mM} \mathrm{NaCl}, 10 \%$ (v/v) glycerol and $1 \mathrm{mM}$ EDTA], loaded on a 5-ml HiTrap SP HP column (GE Healthcare), and eluted with a 100-ml gradient of $150-1000 \mathrm{mM} \mathrm{NaCl}$ in the same buffer. The purified protein fractions were concentrated to $10 \mathrm{mg} / \mathrm{mL}$ and exchanged into the storage buffer [25 $\mathrm{mM}$ Tris- $\mathrm{HCl}(\mathrm{pH} 7.6), 500 \mathrm{mM} \mathrm{NaCl}$ and $30 \%$ (v/v) glycerol]. The purification of $\mathrm{CaPif} 1^{\mathrm{C} 426 \mathrm{~A}}$ and CaPif1 ${ }^{\mathrm{C} 662 \mathrm{~A}}$ followed the same protocol as that for the wide-type CaPif1.

\subsection{Crystallization}

The CaPif1 protein at $10 \mathrm{mg} / \mathrm{mL}$ in $100 \mathrm{mM} \mathrm{NaCl}, 20 \mathrm{mM}$ Tris- $\mathrm{HCl}(\mathrm{pH} 7.6), 2 \mathrm{mM} \mathrm{MgCl}$, and $1 \mathrm{mM}$ DTT was mixed with poly( $\left.\mathrm{T}_{8}\right)$ DNA (5'-TTTTTTTT-3') at a 1:1.2 molar ratio, with ADP.AlF 4 to a final concentration of $1 \mathrm{mM}$. Crystallization trials of this ternary complex was performed at $20^{\circ} \mathrm{C}$ by the sitting-drop vapor diffusion method. Well-diffracted crystals were obtained under conditions of $15 \%$ (v/v) PEG 4k, 100 mM MES (pH 6.5), and 200 mM KNaTatrate. 


\subsection{Data collection and structural determination}

X-ray diffraction data were collected on the beamline BL17U1 at SSRF synchrotron (Shanghai, China) and indexed and scaled with XDS [18]. The initial structure of the CaPif1-poly $\left(\mathrm{T}_{8}\right)-\mathrm{ADP} \cdot \mathrm{AlF}_{4}$ complex was solved by molecular replacement, performed in Phenix [19] with Phaser [20] using the ScPif1 structure (PDB: 5O6D) as the template [21]. The final structure was manually rebuilt with Coot [22] and refined in Phenix. Data collection and refinement statistics are provided in Table 1. The atomic coordinates and structure factor amplitudes of CaPif1-poly $\left(\mathrm{T}_{8}\right)-\mathrm{ADP} \cdot \mathrm{AlF}_{4}$ have been deposited in the Protein Data Bank (PDB: 7OTJ).

\subsection{DNA substrate preparations}

All oligonucleotides (Sangon Biotech, Shanghai) were HPLC-purified (Supplementary Table 1). The partial duplex DNA $S_{26} D_{17}$ used in the stopped-flow assay was heated to $95^{\circ} \mathrm{C}$ in the annealing buffer [20 mM Tris- $\mathrm{HCl}(\mathrm{pH} 8.0)$ and $100 \mathrm{mM} \mathrm{KCl]} \mathrm{and} \mathrm{slowly} \mathrm{cooled} \mathrm{to} \mathrm{room} \mathrm{temperature.}$

\subsection{Fluorescence polarization binding assay}

The apparent dissociation constants of CaPif1 under equilibrium conditions were determined using a fluorescence anisotropy assay. The protein concentration-dependent changes in fluorescence anisotropy were measured with FAM-labeled probes using an Infinite F200 instrument (TECAN). Varying amounts of protein were added to $150 \mu \mathrm{L}$ of binding buffer [50 mM KCl, $20 \mathrm{mM}$ Tris- $\mathrm{HCl}(\mathrm{pH}$ 7.5), 2 $\mathrm{mM} \mathrm{MgCl}$ and $1 \mathrm{mM}$ DTT] with $5 \mathrm{nM}$ FAM-labeled probes. Each sample was allowed to equilibrate in solution at $24^{\circ} \mathrm{C}$ for $5 \mathrm{~min}$. Then, steady-state fluorescence anisotropy was performed. A second reading was taken after 3 min to ensure that the mixture was well-equilibrated and stable. Each experiment was repeated at least 3 times. The equilibrium dissociation constant was determined by fitting the binding curves using the method described previously [23]. 
A stopped-flow assay was used for measuring the helicase activity of CaPif1, according to Duan et al.

[24]. In summary, unwinding kinetics were measured in a 2-syringe mode, where the helicase and fluorescently labeled DNA substrate were pre-incubated at $37^{\circ} \mathrm{C}$ in a syringe for $5 \mathrm{~min}$. Then, the unwinding reaction was initiated by rapidly adding the ATP from the other syringe. The unwinding assays were performed in $25 \mathrm{mM}$ Tris- $\mathrm{HCl}(\mathrm{pH} 7.5)$ containing $25 \mathrm{mM} \mathrm{NaCl}, 2 \mathrm{mM} \mathrm{MgCl}$, and $1 \mathrm{mM}$ DTT. The standard reaction was performed with 4 nM DNA, 1 mM ATP, and $100 \mathrm{nM}$ CaPif1. All stopped-flow kinetic traces were averages of over 10 individual traces. The duplex unwinding kinetic parameters were estimated using the Bio-Logic SFM-400 mixer and the Bio-Logic MOS450/AF-CD optical system (FC-15, Bio-Logic, France) and analyzed as reported [25].

\section{Results and discussion}

\subsection{Crystal structure of CaPif1 with bound DNA and ADP. $\mathrm{AlF}_{4}$}

The 5'-tail of a dsDNA is required for Pif1 helicase to unwind the duplex. The Pif1 helicase core, CaPif1 (CaPif1 $\left.{ }^{368-883}\right)$, displayed a high affinity to poly(T), poly(C), poly(A), and G-rich ssDNA in the presence of an ATP analog (Figure S1). Thus, CaPif1 was crystallized in complex with different ssDNA molecules in the presence of an ATP analog. Subsequently, the ternary complex containing CaPif1, Poly $\left(\mathrm{T}_{8}\right) \mathrm{DNA}$, and nucleotide $\mathrm{ADP} \cdot \mathrm{AlF}_{4}$ was crystallized, and its structure was solved at a resolution of $2.57 \AA$. The asymmetric unit (a.u.) in the $C 121$ space group contained 2 ternary complexes, and 2 CaPif1 molecules in both ternary complex exhibits similar organization that could be superimposed with an r.m.s.d. deviation of $0.258 \AA$ for 282 equivalent $\alpha$-carbon atoms.

CaPif1 helicase core was divided into 5 structural domains: 2 RecA-like domains 1A, at residues 367437 and 457-555, respectively; $2 \mathrm{~A}$, at residues 556-618 and 812-867, respectively; $1 \mathrm{~B}$, at residues 438456; $2 \mathrm{~B}$, at residues 619-682 and 769-811, respectively; and a yeast-specific extra structure domain 2C at residues 683-768 (Figure 1). However, residues 689-752 from domain 2C were not observed in the electron density map. Two RecA-like domains were separated by a cleft that bound and hydrolyzed ATP. Domain 1B formed an extended loop followed by a short helix, known as the "wedge region." Domain 2B adopted an SH3-like fold seen in the structure of RecD2, and the tip of its rail-like $\beta$ hairpin (green in Figures 1b and 1c) was close to domain 1B [26]. The overall structure of the folded CaPif1 was similar to that of other Pif1 family helicases. 


\subsection{ATP binding and hydrolysis}

NTP (dNTP)-binding and hydrolysis are necessary for a helicase to unwind a dsDNA. The ATP analog $\mathrm{ADP} \cdot \mathrm{AlF}_{4}$, bound in the cleft between domains $1 \mathrm{~A}$ and $2 \mathrm{~A}$, was resolved in our structure (Figure $1 \mathrm{~b}$ ). For ATP binding, such as $\mathrm{ADP} \cdot \mathrm{AlF}_{4}$ binding here, CaPif1 showed a similar binding site compared to that in ScPif1 (Figure 2a). The aromatic ring of adenine was found to be stacked by a highly conserved F555. The $\alpha$ - and $\beta$-phosphates were coordinated by interactions with 7 residues, G393-V398 and R556. $\mathrm{AlF}_{4}$ corresponding to the $\gamma$-phosphate of ATP was recognized by G393, K396, Q512, R556, and R847.

The highly conserved Q-motif in helicase involved in the special recognition of adenine bases has already been structurally and functionally described [27]. In CaPif1, the adenine base was found to be specifically recognized by Q373. We verified whether ATP/dATP could be used preferentially in the duplex unwinding process of CaPif1 by conducting a fluorescent stopped-flow helicase activity assay. A partial duplex DNA was used as a substrate. All the measured kinetic curves (Figures 2b and S2) were fitted according to Zhang et al. [25]. The results showed that the unwinding rate of the fast phase with ATP $\left(k_{\mathrm{fast}}=11 \mathrm{~s}^{-1}\right)$ and dATP $\left(k_{\mathrm{fast}}=10 \mathrm{~s}^{-1}\right)$ was significantly higher than that with other deoxyand ribonucleotide triphosphates (Figure 2c). All these structural and biochemical results show that Capifl1 uses the Q-motif to recognize adenine specifically, and it utilizes ATP and dATP more efficiently.

\subsection{Interaction of ssDNA with CaPif1}

S. cerevisiae Pif1was reported to prefer G-rich DNA to non-G-rich DNA, and no hydrogen bonds could be found between the helicase and poly(T) DNA in ScPif1 in complex with poly $\left(\mathrm{T}_{8}\right)$ and ATP $\gamma \mathrm{S}$ (PDB: 5O6D) $[21,28]$. However, our results showed that $C$. albicans Pif1 exhibited a comparable affinity for DNA with poly $(\mathrm{T})$, poly $(\mathrm{C})$ sequences, and G-rich sequences in the absence and presence of $\mathrm{ADP} \cdot \mathrm{AlF}_{4}$ (Figure S1). Thus, we analyzed the interactions between CaPif1 and poly(T) DNA using PDBsum (http://www.ebi.ac.uk/thornton-srv/databases/pdbsum/Generate.html) to delineate the mechanism of CaPif1's binding to ssDNA. The incomplete 6-nt oligo-dT (thymidine base and deoxyribose group of 
dT6 are missing) binding site was found to traverse along a channel that run across the top of domains 2A and $1 \mathrm{~A}$ of CaPif1 in a 5'-to-3' direction (Figure 3a), similar to that observed in other Pif1 helicases [1].

The binding of CaPif1 to poly(T) DNA was found to be mediated mainly by the contacts between the DNA backbone and the protein (Figure 3b), similar to that observed in ScPif1. Specifically, G442 formed a hydrogen bond with the phosphate group of dT4, T432 with dT5, S435 with dT6, R605 with both dT2 and dT3, and S816 with dT3. The imidazole ring of H434 and H818 was found to stack against the deoxyribose group of dT4 and dT2, respectively. All these residues are conserved between CaPif1 and ScPif1.

CaPif1 also demonstrated extensive interactions with the thymidine bases. The 5 '-end dT1 base was stacked by CaPif1's F836. K518 stabilized the dT2 base through hydrophobic interaction. V516 interrupted the base stacking between dT2 and dT3, and L441 disrupted the base stacking between dT4 and dT5 by inserting between the thymidine bases. Notably, 2 amino acids, V517 from domain 1A and N645 from domain 2B, were involved in the interaction with the base of dT2 and dT5, respectively, via hydrogen bonds.

Sequentially, V517 and N645 of CaPif1 correspond to S386 and Q505 of ScPif1. However, S386 and Q505 of ScPif1 are not involved in oligo-dT binding, and no other residues interact with the thymidine bases via hydrogen bonds in the ternary complex structure of ScPif1-poly(T)-ATP $\gamma \mathrm{S}$. Thus, our observation of CaPif1's high affinity for poly(T) ssDNA in the presence of an ATP analog may help explain the difference between CaPif1 and ScPif1 (Figure 3c) [21].

\subsection{Domain 2B movement is necessary for duplex unwinding}

We and others have reported the domains 2B of BsPif1 and ToPif1 undergo a significant rotation upon binding to ssDNA and ATP [15-17]. Domain 2B is in a closed conformation and located near domains 1A in Pif1 apo; it is in an opened conformation and far away from domain 1A in Pif1 in complex with DNA and ATP. On the other hand, the rotation of domain 2B is an important regulatory mechanism in both BsPif1's and ToPif1's helicase activity $[15,17]$.

We probed whether domain $2 \mathrm{~B}$ of $\mathrm{CaPif} 1$ behaved in the same manner by fixing $2 \mathrm{~B}$ on $1 \mathrm{~A}$ by 
crosslinking its cysteines. Five cysteines can be found in the truncated Pif1, C426 and C507 from domain 1A, C584 and C592 from domain 2A, and C662 from domain 2B. C426 is closest to C662 when the domain $2 \mathrm{~B}$ is in an open conformation in the ternary complex $(9.0 \AA$, Figure $4 \mathrm{a})$. Thus, domain 2B in CaPif1 apo was expected to be in the same closed conformation as in BsPif1 and ToPif1 apo, and the spatial distance between C426 and C662 were expected to be closer, thus helping the establishment of a disulfide bridge between the 2 residues and the blocking of the rotation of domain $2 \mathrm{~B}$.

The wild-type CaPif1 without oxygen treatment was found to unfold a partial duplex with normal amplitude and rate in the absence or presence of DTT while showing negligible unwinding activity after a 2-hour oxygen treatment in the absence of DTT (Figures 4b-4d). Moreover, the unwinding activity of the wild-type CaPif1 with oxygen treatment could be rejuvenated with 2-5 mM DTT to reach a level comparable to that of the untreated protein (Figures $4 \mathrm{c}$ and $4 \mathrm{~d}$ ). We designed and purified $\mathrm{CaPif}^{\mathrm{C} 426 \mathrm{~A}}$ and $\mathrm{CaPif} 1^{\mathrm{C} 662 \mathrm{~A}}$ to further analyzed the unwinding activity of CaPif1. After oxygen treatment, the unwinding activities of the 2 mutants were partially rejuvenated compared with that of the wild-type in the absence as well as the presence of DTT (Figures 4c and 4d). Therefore, the unwinding activity of wild-type CaPif1 after oxygen treatment is likely reduced by the formation of a disulfide bridge between C426 and C662 that blocks the rotation of domain 2B. These results together stress the importance of 2B rotation/movement in duplex unwinding by CaPif1.

In summary, we have solved the ternary complex structure of CaPif1-ssDNA-ADP-AlF 4 at high resolution. We have described the binding mechanism of CaPif1 to ssDNA and an ATP analog. Moreover, we found that blocking the potential rotation of domain 2B suppressed the unwinding activity of CaPif1. Our structural and biochemical data provide a foundation for future investigation of the unwinding mechanism of Pif1.

\section{Declaration of competing interest}

No competing financial interests. 


\section{Acknowledgments}

We thank beamline scientists at BL17U1 of the Shanghai Synchrotron Radiation Facility for assistance with data collection. This work was supported by the National Natural Science Foundation of China (No. 31870788) and Northwest A\&F University Startup Funding for Xu-Guang Xi (No. Z101021903). 


\section{References}

[1] M.R. Singleton, M.S. Dillingham, D.B. Wigley, Structure and mechanism of helicases and nucleic acid translocases, Annu Rev Biochem. $76 \quad$ (2007) https://doi.org/10.1146/annurev.biochem.76.052305.115300.

[2] W.H. Chung, To peep into Pif1 helicase: multifaceted all the way from genome stability to repairassociated DNA synthesis, J Microbiol. 52 (2014) 89-98, https://doi.org/10.1007/s12275-014-3524-3.

[3] J.B. Bessler, J.Z. Torres, V.A. Zakian, The Pif1p subfamily of helicases: region-specific DNA helicases?, Trends Cell Biol. 11 (2001) 60-65, https://doi.org/10.1016/s0962-8924(00)01877-8.

[4] M.L. Bochman, N. Sabouri, V.A. Zakian, Unwinding the functions of the Pif1 family helicases, DNA Repair (Amst). 9 (2010) 237-249, https://doi.org/10.1016/j.dnarep.2010.01.008.

[5] J. Zhou, E.K. Monson, S.C. Teng, V.P. Schulz, V.A. Zakian, Pif1p helicase, a catalytic inhibitor of telomerase in yeast, Science. 289 (2000) 771-774, https://doi.org/10.1126/science.289.5480.771.

[6] J.B. Boule, L.R. Vega, V.A. Zakian, The yeast Pif1p helicase removes telomerase from telomeric DNA, Nature. 438 (2005) 57-61, https://doi.org/10.1038/nature04091.

[7] J.E. Pike, R.A. Henry, P.M. Burgers, J.L. Campbell, R.A. Bambara, An alternative pathway for Okazaki fragment processing: resolution of fold-back flaps by Pif1 helicase, J Biol Chem. 285 (2010) 41712-41723, https://doi.org/10.1074/jbc.M110.146894.

[8] C. Ribeyre, J. Lopes, J.B. Boule, A. Piazza, A. Guedin, V.A. Zakian, J.L. Mergny, A. Nicolas, The yeast Pif1 helicase prevents genomic instability caused by G-quadruplex-forming CEB1 sequences in vivo, PLoS Genet. 5 (2009) e1000475, https://doi.org/10.1371/journal.pgen.1000475. 
[9] K. Paeschke, J.A. Capra, V.A. Zakian, DNA replication through G-quadruplex motifs is promoted by the Saccharomyces cerevisiae Pif1 DNA helicase, Cell. 145 (2011) 678-691, https://doi.org/10.1016/j.cell.2011.04.015.

[10] R. Ramanagoudr-Bhojappa, L.P. Blair, A.J. Tackett, K.D. Raney, Physical and functional interaction between yeast Pif1 helicase and Rim1 single-stranded DNA binding protein, Nucleic Acids Res. 41 (2013) 1029-1046, https://doi.org/10.1093/nar/gks1088.

[11] Y. Gu, Y. Masuda, K. Kamiya, Biochemical analysis of human PIF1 helicase and functions of its N-terminal domain, Nucleic Acids Res. 36 (2008) 6295-6308, https://doi.org/10.1093/nar/gkn609.

[12] S.P. Singh, K.N. Koc, J.L. Stodola, R. Galletto, A Monomer of Pif1 Unwinds Double-Stranded DNA and It Is Regulated by the Nature of the Non-Translocating Strand at the 3'-End, J Mol Biol. 428 (2016) 1053-1067, https://doi.org/10.1016/j.jmb.2016.02.017.

[13] A.K. Byrd, K.D. Raney, Structure and function of Pif1 helicase, Biochem Soc Trans. 45 (2017) 1159-1171, https://doi.org/10.1042/BST20170096.

[14] S. Dehghani-Tafti, V. Levdikov, A.A. Antson, B. Bax, C.M. Sanders, Structural and functional analysis of the nucleotide and DNA binding activities of the human PIF1 helicase, Nucleic Acids Res. 47 (2019) 3208-3222, https://doi.org/10.1093/nar/gkz028.

[15] Y.X. Dai, W.F. Chen, N.N. Liu, F.Y. Teng, H.L. Guo, X.M. Hou, S.X. Dou, S. Rety, X.G. Xi, Structural and functional studies of SF1B Pif1 from Thermus oshimai reveal dimerization-induced helicase inhibition, Nucleic Acids Res. 49 (2021) 4129-4143, https://doi.org/10.1093/nar/gkab188.

[16] X. Zhou, W. Ren, S.R. Bharath, X. Tang, Y. He, C. Chen, Z. Liu, D. Li, H. Song, Structural and 
Functional Insights into the Unwinding Mechanism of Bacteroides sp Pif1, Cell Rep. 14 (2016) 20302039, https://doi.org/10.1016/j.celrep.2016.02.008.

[17] W.F. Chen, Y.X. Dai, X.L. Duan, N.N. Liu, W. Shi, N. Li, M. Li, S.X. Dou, Y.H. Dong, S. Rety, X.G. Xi, Crystal structures of the BsPif1 helicase reveal that a major movement of the 2B SH3 domain is required for DNA unwinding, Nucleic Acids Res. 44 (2016) 2949-2961, https://doi.org/10.1093/nar/gkw033.

[18] W. Kabsch, Xds, Acta Crystallogr D Biol Crystallogr. 66 (2010) 125-132, https://doi.org/10.1107/S0907444909047337.

[19] P.D. Adams, P.V. Afonine, G. Bunkoczi, V.B. Chen, I.W. Davis, N. Echols, J.J. Headd, L.W. Hung, G.J. Kapral, R.W. Grosse-Kunstleve, A.J. McCoy, N.W. Moriarty, R. Oeffner, R.J. Read, D.C. Richardson, J.S. Richardson, T.C. Terwilliger, P.H. Zwart, PHENIX: a comprehensive Python-based system for macromolecular structure solution, Acta Crystallogr D Biol Crystallogr. 66 (2010) 213-221, https://doi.org/10.1107/S0907444909052925.

[20] A.J. McCoy, R.W. Grosse-Kunstleve, P.D. Adams, M.D. Winn, L.C. Storoni, R.J. Read, Phaser

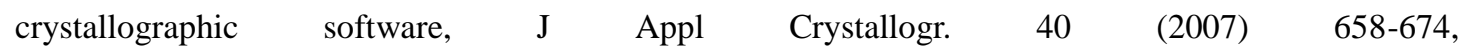
https://doi.org/10.1107/S0021889807021206.

[21] K.Y. Lu, W.F. Chen, S. Rety, N.N. Liu, W.Q. Wu, Y.X. Dai, D. Li, H.Y. Ma, S.X. Dou, X.G. Xi, Insights into the structural and mechanistic basis of multifunctional $S$. cerevisiae Piflp helicase, Nucleic Acids Res. 46 (2018) 1486-1500, https://doi.org/10.1093/nar/gkx1217.

[22] P. Emsley, B. Lohkamp, W.G. Scott, K. Cowtan, Features and development of Coot, Acta Crystallogr D Biol Crystallogr. 66 (2010) 486-501, https://doi.org/10.1107/S0907444910007493. 
[23] N.N. Liu, X.L. Duan, X. Ai, Y.T. Yang, M. Li, S.X. Dou, S. Rety, E. Deprez, X.G. Xi, The Bacteroides sp. 3_1_23 Pif1 protein is a multifunctional helicase, Nucleic Acids Res. 43 (2015) 89428954, https://doi.org/10.1093/nar/gkv916.

[24] X.L. Duan, N.N. Liu, Y.T. Yang, H.H. Li, M. Li, S.X. Dou, X.G. Xi, G-quadruplexes significantly stimulate Pif1 helicase-catalyzed duplex DNA unwinding, J Biol Chem. 290 (2015) 7722-7735, https://doi.org/10.1074/jbc.M114.628008.

[25] X.D. Zhang, S.X. Dou, P. Xie, J.S. Hu, P.Y. Wang, X.G. Xi, Escherichia coli RecQ is a rapid, efficient, and monomeric helicase, J Biol Chem. 281 (2006) 12655-12663, https://doi.org/10.1074/jbc.M513089200.

[26] K. Saikrishnan, B. Powell, N.J. Cook, M.R. Webb, D.B. Wigley, Mechanistic basis of 5'-3' translocation in SF1B helicases, Cell. 137 (2009) 849-859, https://doi.org/10.1016/j.cell.2009.03.036.

[27] N.K. Tanner, O. Cordin, J. Banroques, M. Doere, P. Linder, The Q motif: a newly identified motif in DEAD box helicases may regulate ATP binding and hydrolysis, Mol Cell. 11 (2003) 127-138, https://doi.org/10.1016/s1097-2765(03)00006-6.

[28] K. Paeschke, M.L. Bochman, P.D. Garcia, P. Cejka, K.L. Friedman, S.C. Kowalczykowski, V.A. Zakian, Pif1 family helicases suppress genome instability at G-quadruplex motifs, Nature. 497 (2013) 458-462, https://doi.org/10.1038/nature12149. 
Table 1

Data collection and refinement statistics of CaPif1-poly $\left(\mathrm{T}_{8}\right)-\mathrm{ADP} \cdot \mathrm{AlF}_{4}$ complex.

\begin{tabular}{|c|c|}
\hline Data Set & CaPif1-poly $\left(\mathrm{T}_{8}\right)-\mathrm{ADP} \cdot \mathrm{AlF}_{4}$ \\
\hline \multicolumn{2}{|l|}{ Data collection } \\
\hline Wavelength & 0.977 \\
\hline Resolution range $(\AA)$ & $82.51-2.57(2.66-2.57)$ \\
\hline Space group & $C 121$ \\
\hline \multicolumn{2}{|l|}{ Cell dimension } \\
\hline$a, b, c(\AA)$ & 198.9779 .9694 .11 \\
\hline$\alpha, \beta, \gamma\left(^{\circ}\right)$ & 90117.2890 \\
\hline Multiplicity & $3.4(3.5)$ \\
\hline Completeness (\%) & $96.51(99.37)$ \\
\hline Mean I/sigma (I) & $9.24(2.16)$ \\
\hline$R_{\text {merge }}$ & $0.085(0.403)$ \\
\hline Unique reflections & $40378(4106)$ \\
\hline \multicolumn{2}{|l|}{ Refinement } \\
\hline Reflections used in refinement & $40316(4092)$ \\
\hline Reflections used for R-free & $2072(181)$ \\
\hline$R_{\text {work }}(\%)$ & $20.9(27.9)$ \\
\hline$R_{\text {free }}(\%)$ & $23.6(33.9)$ \\
\hline Protein residues & 866 \\
\hline Bond lengths ( & 0.005 \\
\hline Bond angles $\left({ }^{\circ}\right)$ & 1.14 \\
\hline Ramachandran favored (\%) & 99.17 \\
\hline Ramachandran allowed (\%) & 0.83 \\
\hline Ramachandran outliers (\%) & 0.00 \\
\hline PDB ID & 7OTJ \\
\hline
\end{tabular}

Statistics for the highest-resolution shell are shown in parentheses. 


\section{Figure captions}

Figure 1. Structure of the CaPif1-ssDNA-ADP-AIF 4 ternary complex. (a) The domain structure of

CaPif1. (b and c) The structure of the CaPif1-ssDNA-ADP-AlF 4 complex shown in cartoon (b) and surface (c), with domain 1A (blue), 2A (red), 1B (magenta), 2B (orange), 2C (yellow), and C-terminal domain (CTD; gray).

Figure 2. CaPif1 exhibits a preference for ATP and dATP. (a) Detailed view of the nucleotidebinding site of $\mathrm{CaPif1}$ with $\mathrm{ADP} \cdot \mathrm{AlF}_{4}$. (b) Stopped-flow kinetic traces for the unwinding of partial duplex DNA $\left(\mathrm{S}_{26} \mathrm{D}_{17}\right)$ with different dNTPs. The unwinding rate of the fast phase (c) was determined from the fittings using a previously reported equation [26].

Figure 3. CaPif1 binds to ssDNA. (a) Detailed view of the interactions between ssDNA and CaPif1. The amino acids involved in DNA binding are colored according to domain colors defined in Figure 1 (domain 1A, blue; 2A, red; 1B, magenta; and 2B, orange) and presented in sticks. (b) The interaction between CaPif1 and Poly(T) DNA. (c) The ssDNA binding curves of CaPif1 determined with Poly $\left(\mathrm{T}_{12}\right)$ and $\mathrm{GR}_{12}$ (12-nt G-rich ssDNA) in the absence (left panel) or presence (right panel) of $1 \mathrm{mM} \mathrm{ADP} \cdot \mathrm{AlF}_{4}$

Figure 4. CaPif1 unwinding activity is suppressed by crosslinking. (a) The distance between C426 and $\mathrm{C} 662$ in the presence of ssDNA and $\mathrm{ADP} \cdot \mathrm{AlF}_{4}$. (b) The unwinding kinetic curves of various versions of CaPif1 with or without oxygen in the absence of DTT. (c) and (d) show the fractions of the unwinding rate and amplitude determined from the unwinding curves in Figure S3. Wild-type and 2 mutant CaPif1 were treated with oxygen for 2 hours; then, $100 \mathrm{nM}$ CaPif1 and $4 \mathrm{nM}$ fluorescentlabeled $\mathrm{S}_{26} \mathrm{D}_{17}$ were used for DNA unwinding kinetic assays with increasing DTT concentrations. Wildtype CaPif1 without oxygen treatment was used as the control for the DNA unwinding kinetic assays. 
Figure 1

(a)

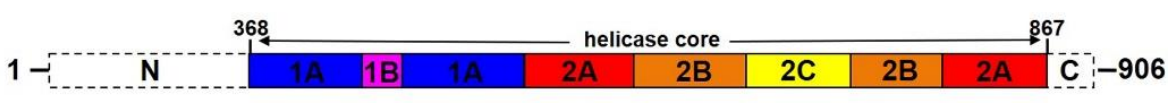

(b)

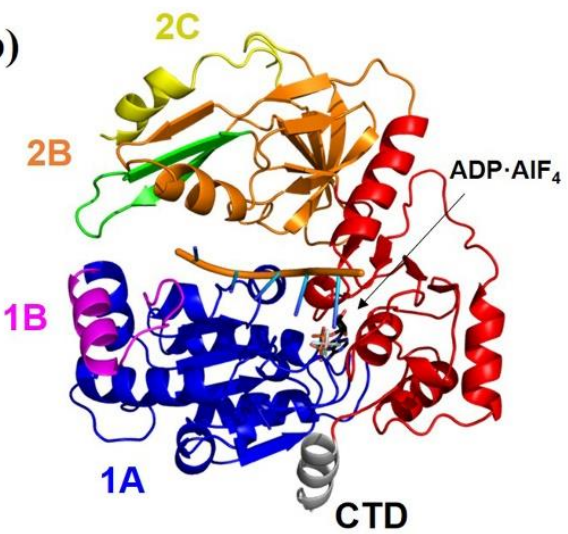

(c)

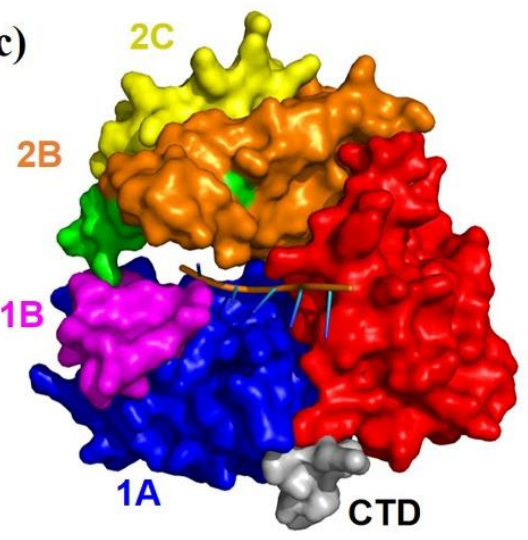

Figure 2

(a)

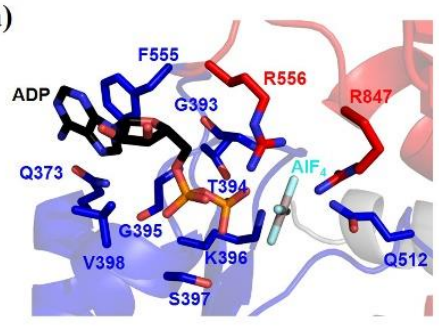

(b)

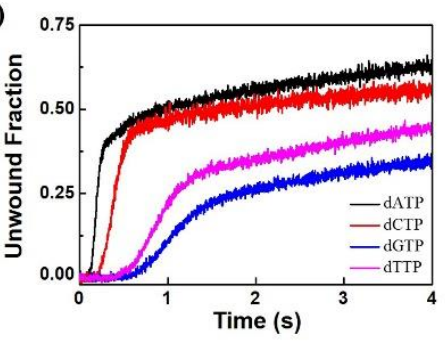

(c)

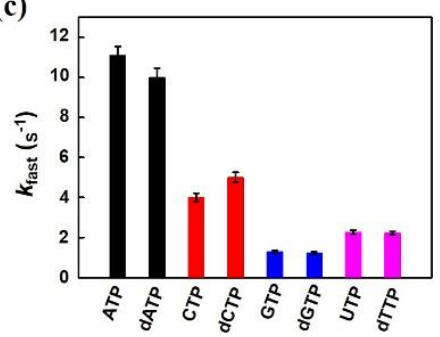

Figure 3

(a)

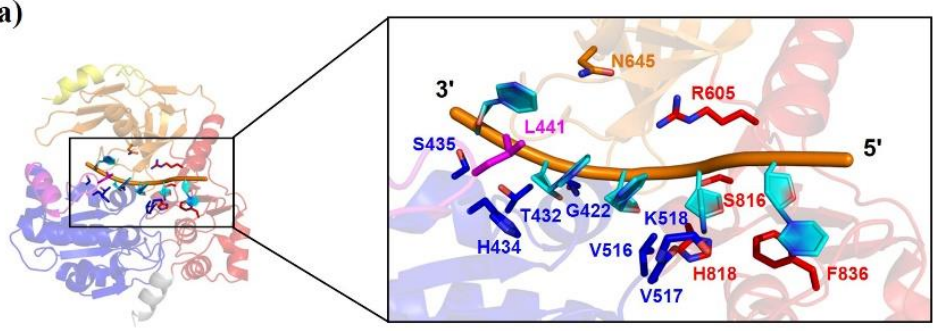

(b)

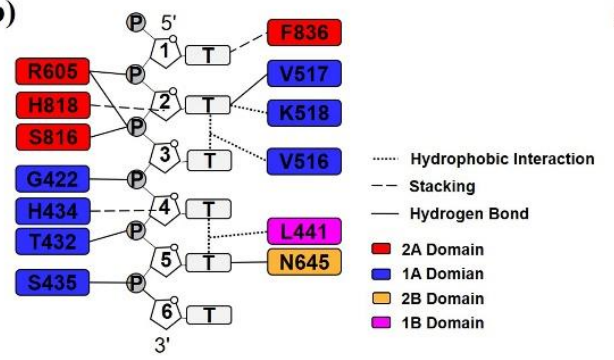

(c)

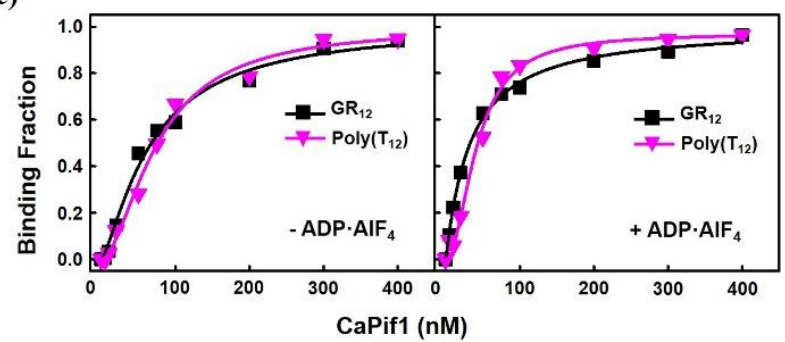


Figure 4

(a)

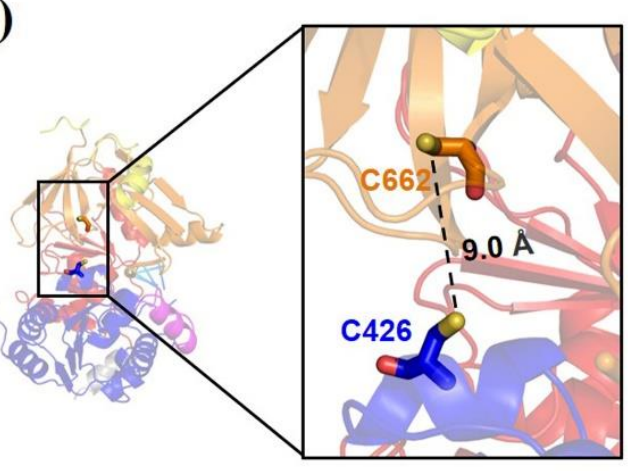

(c)

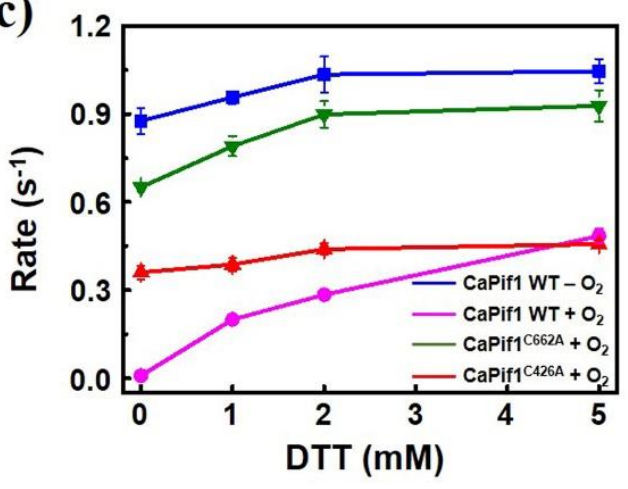

(b)

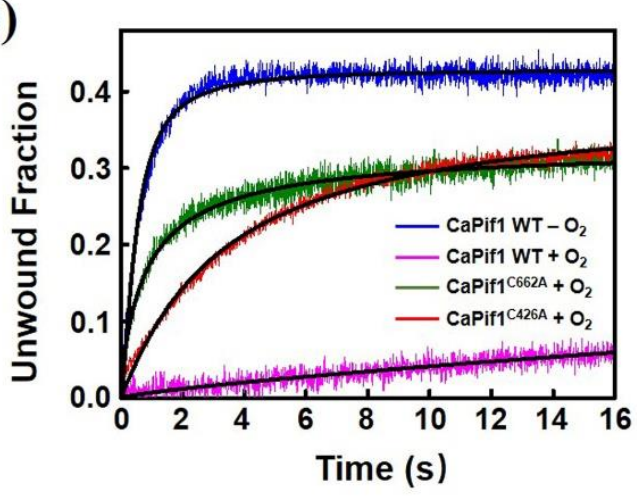

(d)

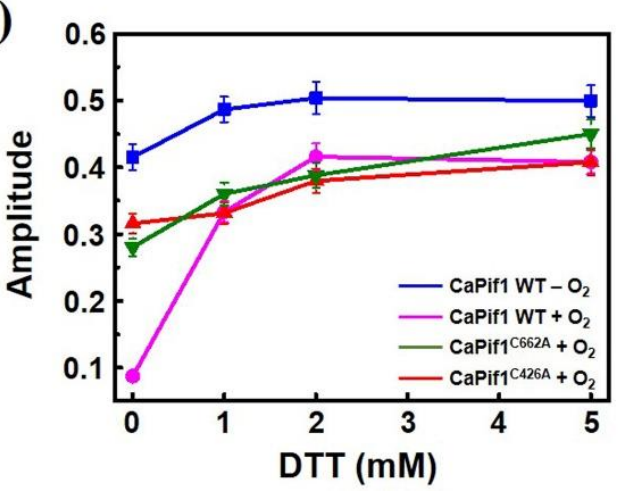




\section{Supplementary material}

\section{Supplementary Table 1}

Oligonucleotides used in this study

\begin{tabular}{|c|c|}
\hline Names & Oligo sequences $\left(5^{\prime}-3^{\prime}\right)$ \\
\hline Poly $\left(T_{8}\right)$ & TTTTTTTT \\
\hline $\operatorname{Poly}\left(\mathrm{T}_{12}\right)$ & ТTTTTTTTTTTT-F \\
\hline $\operatorname{Poly}\left(\mathrm{A}_{12}\right)$ & AAAAAAAAAAAA-F \\
\hline $\operatorname{Poly}\left(\mathrm{C}_{12}\right)$ & CСССССССССCC-F \\
\hline $\mathrm{GR}_{12}$ & GTGTGTGTGTGT-F \\
\hline $\mathrm{S}_{26} \mathrm{D}_{17}$ & $\begin{array}{l}\text { TTTTTTTTTTTTTTTTTTTTTTTTTTATGTATGTCAAGGAAGG-F } \\
\text { HF-CCTTCCTTGACATACAT }\end{array}$ \\
\hline
\end{tabular}

F represents Fam. HF represents hexachlorofluorescein. 


\section{Supplementary Figure captions}

Figure S1. The ssDNA binding curves of CaPif1 determined with Poly $\left(\mathrm{T}_{12}\right), \mathrm{GR}_{12}$ (12-nt G-rich ssDNA), Poly $\left(\mathrm{C}_{12}\right)$, and Poly $\left(\mathrm{A}_{12}\right)$ in the absence (left panel) or presence (right panel) of $1 \mathrm{mM}$ $\mathrm{ADP} \cdot \mathrm{AlF}_{4}$

Figure S2. The stopped-flow kinetic traces for partial duplex DNA unwinding with different NTPs in the presence of $1 \mathrm{mM}$ DTT were used to determine the unwinding rate $k_{\text {fast }}$ (Figure $2 \mathrm{c}$ ).

Figure S3. The detailed unwinding kinetic curves of various version of CaPif1 with or without oxygen treatment with increasing DTT concentrations. 
Figure S1

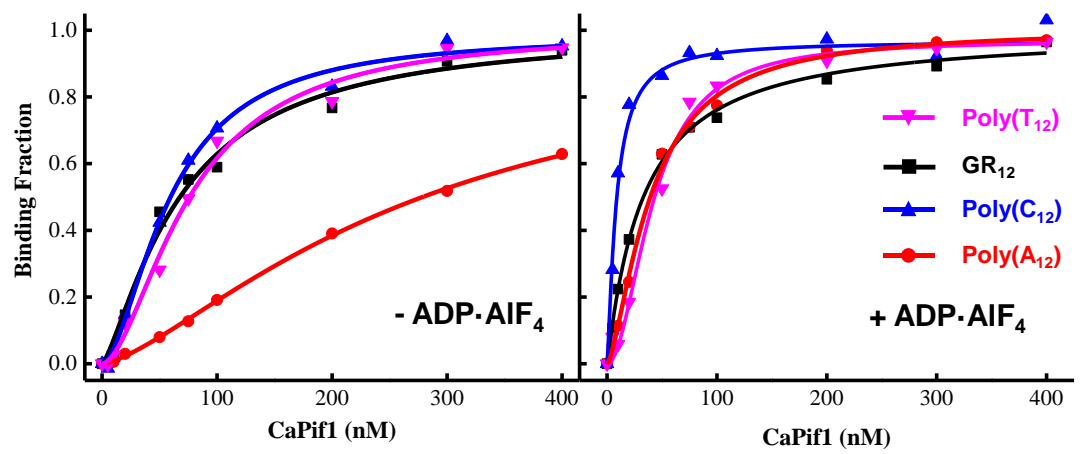

Figure S2

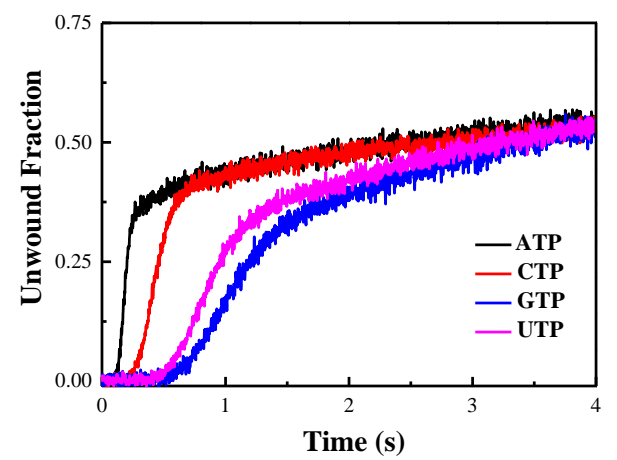

Figure S3

(a)

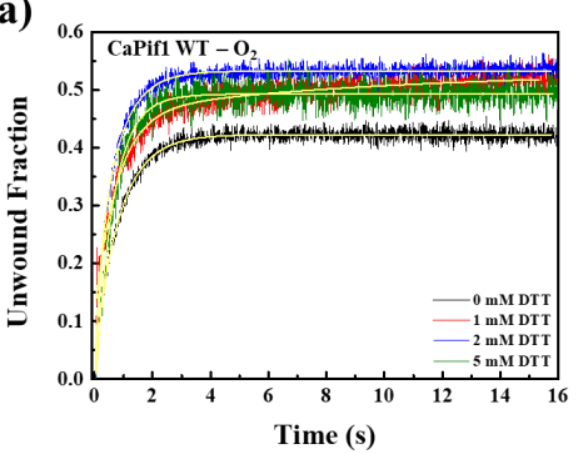

(c)

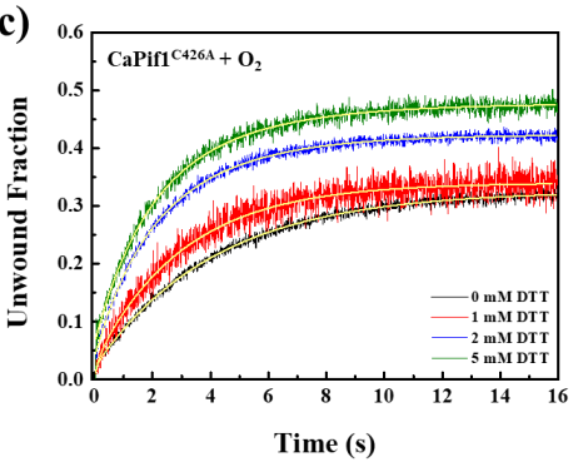

(b)

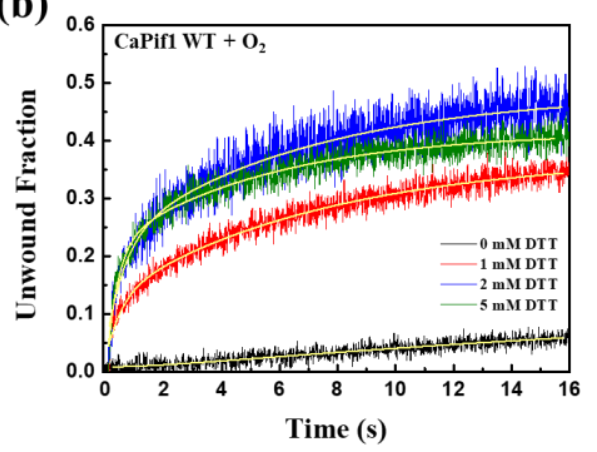

(d)

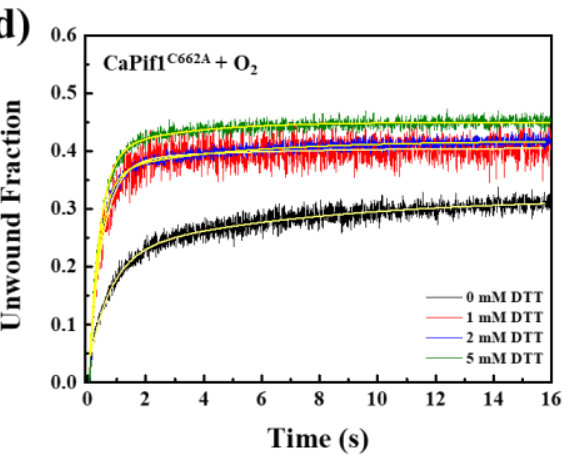


